\title{
Knowledge and Utilization of Electronic Health Record in Healthcare Delivery in Kwadaso S.D.A Hospital, Kumasi
}

\author{
Kennedy Addo* \\ Department of Health Sciences \\ Garden City University College, Kumasi, Ghana \\ P.O BOX 12775 \\ kenaddo90@yahoo.com \\ $+233246890717$ \\ *Corresponding Author \\ Pabbi Kwaku Agyepong \\ Department of Computer Science \\ Kwame Nkrumah University of Science and Technology, Kumasi, Ghana \\ University Post Office \\ kwakupabbi@yahoo.co.uk \\ $+233574618818$ \\ DOI: $10.31364 /$ SCIRJ/v8.i7.2020.P0720786 \\ http://dx.doi.org/10.31364/SCIRJ/v8.i7.2020.P0720786
}

\begin{abstract}
Background: There has been a lot of development in the healthcare industry and this development has led to a change in the tools being used by healthcare professionals in their field of work. The traditional paper-based medical record has been replaced with the Electronic Health Record (EHR).

Objective: The main purpose of the study was to assess the knowledge and utilization of electronic health record in healthcare delivery in Kwadaso S.D.A Hospital, Kumasi.

Methods: The study adopted a descriptive cross-sectional survey which was quantitative approach in nature in achieving the objectives of the study. A purposive sampling technique was adopted for this study and of which 100 respondents were sampled to be part of the study. The data was collected through the use of semi-structured interview and questionnaire from the sampled respondents. The data was keyed into statistical software (Statistical Product and Service Solutions, SPSS version 24.0) and expressed in frequency distribution tables and charts.

Results: the study reported that almost all of the respondents have ever used EHR system to collect patient's information, keeping laboratory records, among others. Moreover, majority of the respondents representing $80 \%$ chose the benefits of the implemented EHR system over paper-based system as it was suggested to significantly facilitate easy accessibility of patients' records and improvement in overall quality health services delivery. Contrary to the above finding, the study uncovered some challenges that hamper the smooth functionality of the system due to inadequate computer knowledge and frequent power outages that resulted in frequent system downtime with its resultant effect on lack of interest in using the implemented EHR system.

Conclusion: the study recommends that the hospital take proactive steps in motivating and training end-users on the EHR system periodically to encourage acceptance and usability among the staff.
\end{abstract}

Keywords: Electronic Health Records, Information Technology, Internet, Information and Communication Technology

\section{INTRODUCTION}

There has been a lot of development in the healthcare industry and this development has led to a change in the tools being used by healthcare professionals in their field of work. The traditional paper-based medical record has been replaced with the Electronic Health Records (EHR). This important shift which is the growing use of EHR has been the focus of attention over the past years [1]. At present, 21 out of 138 public hospitals which are made up 15.2\% public hospitals implemented the system [2].

www.scirj.org

(C) 2020, Scientific Research Journal

http://dx.doi.org/10.31364/SCIRJ/v8.i7.2020.P0720786

This publication is licensed under Creative Commons Attribution CC BY. 
In the case of Ghana, eHealth system is still at the infant stage where a lot of hospitals are still at the partial stage of implementation and others at its piloting stage [3].

Electronic health record (EHR) systems, which have the potential of improving the quality and reliability of health information and communication and the overall quality of healthcare services, are also not left out in the ICT implementation in the Ghanaian health care system. It is very essential to have precise, reliable and timely data given the complicated nature of healthcare delivery and the many choices that need to be made, sometimes in very difficult situations. Paper-based records lack the flexibility and optimal support comparable to EHR [4]. The Ministry of Health in Ghana has bemoaned having disparate and redundant data flows and therefore the need to have this addressed.

Over the years, the government has put in place a number of measures to enhance the quality of care. Unfortunately, these approaches have not yielded the needed results due to the absence of timely and accurate data [3]. However, only a few major organizations have worked on the implementation of EHR systems with fewer than half of clinicians having EHRs with capabilities of performing multiple functions that can help in clinical decisions and electronic prescription. Undeniably, the challenges that gainsay the implementation of EHR can never be overlooked. Many large clinics and hospitals have already implemented the use of EHR. However, in clinics where health care practitioners are 1-3, and the cost of implementation has slowed down the adaption rate [5]. According to a study done in 2012, it was revealed that out of the four major hospitals in Ghana including; Korle-Bu Teaching Hospital (KBTH), Effia Nkwanta Regional Hospital (ENRH), Komfo Anokye Teaching Hospital (KATH), and Tamale Teaching Hospital (TTH), only KATH had partially adopted EHR in few departments of the facility whilst the other above named hospitals were in the process of migrating from paper-based work to EHR systems or yet to consider one. User adoption rate was scanty and the health facilities in transition found it hard to maintain information. Despite the problems, enhancing patient care quality and effectiveness in the medical setting made it worth implementing one. The services rendered must exemplify the knowledge level of health professionals with focus on standards and customers' market expectations [6]. Hence, the research seeks to assess the knowledge and utilization of EHR in healthcare delivery in Kwadaso SDA hospital, Kumasi. It is hoped that the results of the study will highlight the current status of knowledge and utilization of EHR in healthcare delivery in Kwadaso S.D.A Hospital, Kumasi.

\section{Research Methodology}

\section{Study Setting}

The study was conducted at the Kwadaso S.D.A hospital. This hospital is situated in the Kumasi Metropolis of Ashanti Region of Ghana. Kwadaso constituency is one of two constituencies which were carved out of Bantama by legislative instrument in 2004 during the creation of new districts in Ghana. The constituency is regarded as one of the largest among the other constituencies in the Ashanti region.

The inhabitants are mostly Akans and Twi is the major language spoken. Other tribes like Fantes, Ewes, Dagomba and Frafra among others are also found in the community. The main occupation is trading, however, quite a sizable number are engaged in office work. The area of Kwadaso covers a land of about 750 kilometer square which is approximately 45\% of the total geographical area of 1361 kilometer square covered by the entire district. The Seventh Day Adventist Hospital offers services such as surgical, dental, eye, ear and throat, orthopedic, maternal and child health with a bed capacity of 72 .

\section{Study design.}

The study employed a cross-sectional exploratory design. This design involves a quantitative approach and it deals with numerical analysis of data. This design was selected to explore the phenomenon under study. It also aided in the generalization of findings.

\section{Study Population}

The study population in this study was individuals working at the Kwadaso SDA Hospital in the Ashanti Region. The respondents in this study included; Administrators, Doctors, Nurses, Midwives, Medical Records, Laboratory, Pharmacy, ICT staff, Finance

\section{Sampling and sampling technique.}

The purposive sampling technique was used to recruit participants for the study because the subjects or participants had certain characteristics that are of interest to the researcher. Hence, hundred (100) respondents were selected to represent the target population for the study.

\section{Data collection Approach}

A structured questionnaire was developed and used as the tool for data collection. The questionnaire had four sections; section A, B, C, and D. Section A focused on demographic data, section B covered the usability and acceptance of EHR, section C focused on the impact of EHR systems on quality service delivery among staff and clients, and section D looked at the barriers/challenges of EHR systems among staff. Formal permission was sought from the heads of Kwadaso SDA hospital, to conduct the study. The in-charge in the various units served as contact persons to help in the recruitment of the study participants. Those who were able to complete it the same day had their questionnaire collected. Those who did not complete the questionnaire were allowed to take it home and return it the following day. This was done to allow them have enough time to fill the questionnaire in a relaxed atmosphere without any

www.scirj.org

(C) 2020, Scientific Research Journal

http://dx.doi.org/10.31364/SCIRJ/v8.i7.2020.P0720786

This publication is licensed under Creative Commons Attribution CC BY. 
interferences. Data collection was carried out within a period of four (4) weeks and each participant used 30 minutes to answer the questions.

\section{Data Analysis.}

The data collected was coded, entered and analysed in detail using statistical software Excel 2016 to generate the results for discussion. Statistical instruments such as percentages and tables were employed.

\section{Validity and reliability}

To ensure accuracy of information, a drafted questionnaire consisting of ten (10) research questionnaires were pre-tested at SDA hospital and the questionnaires were analysed and all omissions and additions were made where necessary. Data handling and storage was done where questionnaires were numbered serially to allow for easy identification in the sequence in which they were filled and collected to avoid repetition. Questionnaire was checked for errors and completeness before entry into database in order to ensure that reliable results are obtained.

\section{Ethical Considerations.}

Formal permission was sought from the Municipal Assembly, Medical director, and Nursing Manager of SDA hospital in the conduct of the study. Moreover, verbal consent form was sought from the respondents before the questionnaire was administered. Respondents were informed that they could opt out of the study if they wanted to do so. Names of participants were not recorded in order to ensure anonymity and all information which was provided was treated as confidential.

\section{Table 1}

Results

Table 1: Socio-demographic Information of Respondents

Variable

Gender
Male
Female
Age (in years)
20-25 years
26-30 years
31-35 years
36-40 years
41 years and above
Profession
Doctor
Hospital administrator
Hospital IT staff
Pharmacist
Nurse
Record Officer
Laboratory Technician
Level of formal Education
Certificate
Diploma
Degree
Master's Degree
PhD
Religion
Christianity
Islamic
Number of years work in the facility
1-3
4-6 years
7-9 years
10-12
Department
Emergency
OPD
Medical ward
Surgical ward
Laboratory
Pharmacy
IT department
Administration

$\begin{array}{rr}42 & \\ 58 & 52 \\ & 58 \\ 8 & 8 \\ 32 & 32 \\ 9 & 45 \\ 6 & 9 \\ & \end{array}$

42
58

8

$79 \quad 79$


ENT

MBU

Pediatric

Theatre

Psychiatric department

Maternity

Eye clinic

Children ward

Male's ward

\begin{tabular}{rr}
10 & 10 \\
10 & 10 \\
4 & 4 \\
4 & 4 \\
7 & 7 \\
2 & 2 \\
2 & 2 \\
2 & 2 \\
\hline
\end{tabular}

On gender distribution of participants, the study reveals that $58(58.0 \%)$ of the respondents were female whereas the rest $42(42.0 \%)$ were males. The study depicts that majority that is $45(45.0 \%)$ of the respondents were aged between 31-35 years, followed by $32(32.0 \%)$ were within $26-30$ years, $9(9.0 \%)$ aged from 36-40 years. The rest of the results are illustrated in table 1. Majority of the respondents that is $83(83.0 \%)$ were nurses, $5(5.0 \%)$ were record officers, $4(4.0 \%)$ were doctors and hospital IT staff respectively and $2(2.0 \%)$ were laboratory technicians. The study discloses that most of the respondents that is $44(44.0 \%)$ of the respondents were diploma holders, $30(30.0 \%)$ were degree holders, $18(18.0 \%)$ were certificate holders and 2(2.0\%) were Masters' degree and $\mathrm{PhD}$ holders respectively. Furthermore, the study reveals that 79(79.0\%) of the respondents were Christians and 21(21.0\%) were Muslims. On the number of years respondents have worked in the facility, majority that is $47(47.0 \%)$ said between $1-3$ years, 26(26.0\%) between 4-6 years, 21(21.0\%) between 7-9 years and the rest representing 6(6.0\%) between 10-12 years. On the department/ward of respondents, it was observed that $13(13.0 \%)$ were respectively in the emergency and medical ward, 10(10.0\%) were in the ENT and Mother-Baby-Unit (MBU), 9(9.0\%) were OPD department, 8(8.0\%) being surgical ward, 7(7.0\%) from the psychiatric department. The rest of the results are found on the table above.

\section{Usability and Acceptance of Electronic Health Record (EHR)}

On respondent's usability and acceptance EHR, it was observed from the study that 70(70.0\%) of the respondents were not incharges in the department/unit whereas 30(30.0\%) were in-charge in their various departments. On the number of years respondents have worked in the department/unit, majority representing 84(84.0\%) stated between 1-3 years, 14(14.0\%) said between 4-6 years and $2(2.0 \%)$ within 7-9 years. Majority of the respondents that is $89(89.0 \%)$ have used EHR for about 1-5 years, $9(9.0 \%)$ for less than a year and 2(2.0\%) between 6-10 years. Majority of the respondents 70(70.0\%) use EHR to enter patients' data/patient's information, $25(25.0 \%)$ to keep laboratory records, and 5(5.0\%) to solve technical problems.

Although most of the respondents found it difficult to use the EHR since they encountered problems when entering data, however, majority depicting $76(76.0 \%)$ chose EHR over paper-based, 20(20.0\%) preferred paper-based to EHR and the rest $4(4.0 \%)$ were conversant with both.

Moreover, out of the $(n=76)$ who chose EHR over paper-based, about $33(43.4 \%)$ claimed that EHR is very convenient to use, $25(32.8 \%)$ said it makes data easily accessible, $8(10.5 \%)$ said it saves time, $4(5.3 \%)$ respectively indicated that it reduces medical errors and has huge storage capacity and the rest $2(2.6 \%)$ said it helps retrieve patients past medical history easily.

Majority that is $76(76.0 \%)$ of the respondents agreed that EHR is worth the time and effort required to use and $24(24.0 \%)$ contended with the above assertion. Among the $(n=76)$ who agreed that EHR is worth the time and effort required to use, closed to 40(52.6\%) revealed it saves time, $19(25.0 \%)$ said it provides effective patient care, 11(14.5\%) disclosed that the features are easy to use, 4(5.3\%) reported that it improves coordination of patient care and 2(2.6\%) indicated that it makes documentation easy compare to paper-based work.

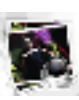

Figure 1.eps

Fig 1: Respondents view on EHR and Paper-based system

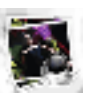

Figure 2.eps

\section{Fig 2: Respondents level of Satisfaction in using EHR}

In assessing respondents' level of satisfaction with the use of EHR, 63(63.0\%) of the respondents were mostly satisfied with the use of EHR. However, 22(22.0\%) were not satisfied at all and 15(15.0\%) were somewhat satisfied. Those impressed about the

www.scirj.org

(C) 2020, Scientific Research Journal

http://dx.doi.org/10.31364/SCIRJ/v8.i7.2020.P0720786

This publication is licensed under Creative Commons Attribution CC BY. 
functionality of the system revealed that EHR system provides the needed flexibility, it is fast, validate data timely, reduces error rates, backup makes data safe, compatible with other system, records are readily available and confidentiality of patients information are well secured respectively.

\section{Challenges Affecting the Implementation and Use of EHR System}

On a scale of $1-5$, with 1 being the least and 5 being the highest, respondents were kindly asked to indicate their level of satisfaction with EHR as shown in table 2.

Table 2: Challenges Affecting the Implementation and Use of EHR System

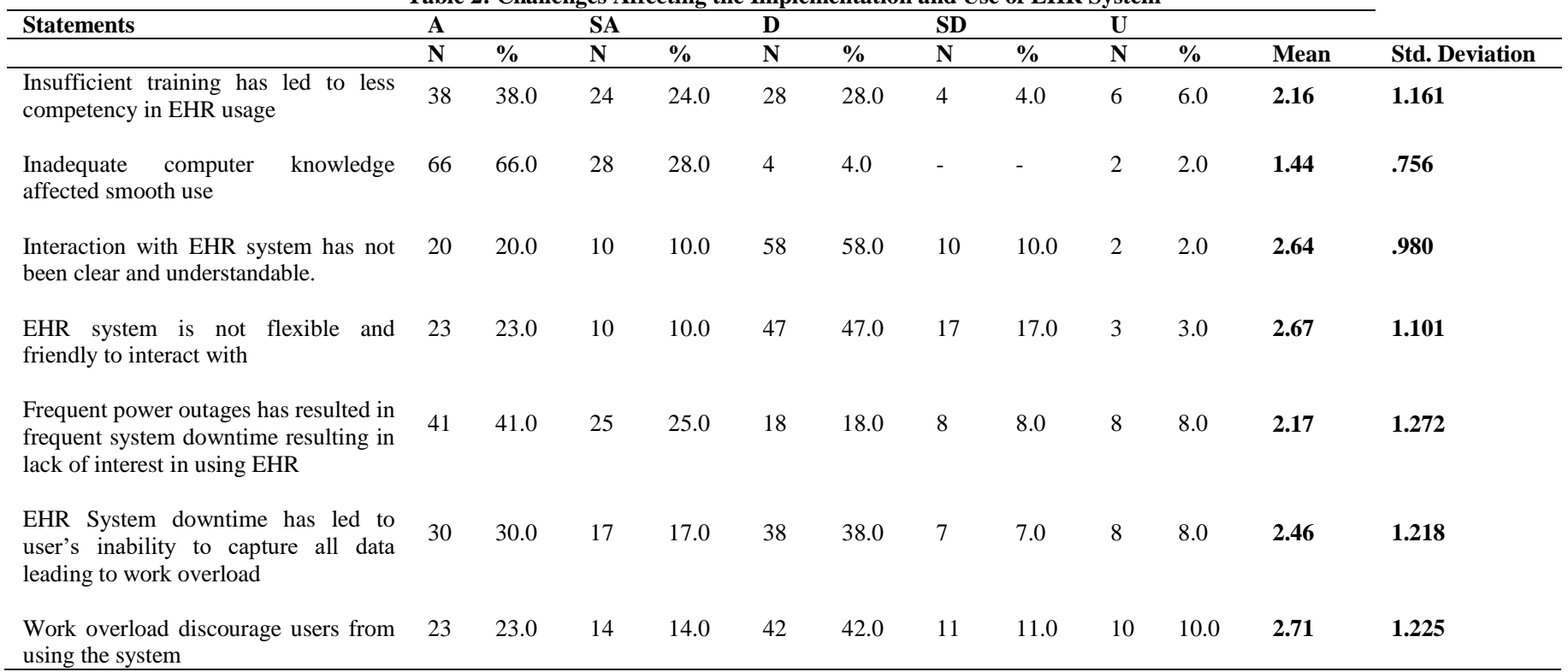

\footnotetext{
Agree (A); Strongly Agree (A); Disagree (D); Strongly Disagree (SD) and Uncertain (U).
}

On the challenges affecting the implementation and use of EHR system, table 2 shows that with a mean value greater or equal to 3.5, majority of the respondents disagreed to the following statement about EHR: (3.06) frequent downtimes led to EHR system unreliability, hence resisting usage and (3.11) lack of reconciliation between EHR system workflow and business workflow. However, $38(38.0 \%)$ agreed that insufficient training led to less competency in EHR usage and 28(28.0\%) contended. From the study, about 94(94.0\%) agreed and strongly agreed that inadequate computer knowledge affected smooth use of EHR whereas 4(4.0\%) disagreed and $2(2.0 \%)$ were uncertain to the statement.

Furthermore, the study revealed that 58(58.0\%) disagreed that their interaction with EHR system was clear and understandable while 20(20.0\%) agreed and 2(2.0\%) were not sure of the aforementioned statement. Majority, that is $47(47.0 \%)$ of the respondents claimed that EHR system to be flexible and friendly to interact with. Moreover, 66(66.0\%) of the respondents agreed and strongly agreed that frequent power outages have resulted in frequent system downtime resulting in lack of interest in using EHR. Nevertheless, 26(26.0\%) disagreed and strongly disagreed that frequent system downtime did not result in lack of interest in using EHR.

It is indicated that $38(38.0 \%)$ of the respondents disagreed that EHR System downtime has not led to user's inability to capture all data, hence leading to work overload. However, 30(30.0\%) agreed that EHR System downtime has led to user's inability to capture all data leading to work overload and $8(8.0 \%)$ were undecided. The study shows that $42(42.0 \%)$ of the respondents contends that work overload did not discourage users from using the system. But 23(23.0\%) asserted that work overload discourages users from using the system and 10(10.0\%) were not sure as to whether work overload discourages users from using the system or not. The study found that $38(38.0 \%)$ of the respondents agreed that lack of on field technical support during implementation affected the system use, $25(25.0 \%)$ disagreed to the statement and 11(11.0\%) were undecided.

\section{Discussion}

The objectives considered under this study included usability and acceptance of EHR system, benefits of EHR on quality of care and challenges affecting the implementation and utilisation of EHR System. These were examined under three research questions. A critical analysis of the results and comparison of the results with similar studies has been done in the discussion.

www.scirj.org

(C) 2020, Scientific Research Journal

http://dx.doi.org/10.31364/SCIRJ/v8.i7.2020.P0720786

This publication is licensed under Creative Commons Attribution CC BY. 


\section{Usability and Acceptance of EHR System}

With regards to usability and acceptance of EHR system among respondents, the study reported that almost all of them have ever used EHR system to collect patient's information, keeping laboratory records, among others. This could be attributed to its safety use, effectiveness and efficiency as recorded in another study by [7] who reported that hospitals that used EHRs or other HIS perform better compare to hospitals that do not. The study found that $35.0 \%$ of the respondents never encountered problems when using the EHR system, however, about $65.0 \%$ sometimes, always and rarely encountered problems such as network problems, slow Internet connection, unstable electricity, system failure, time consuming, technical issue and computer illiteracy. [8] asserts that cost, affordable technology, lack of technical expertise, personal computing skills and the lack of data processing facilities in many developing nations are major issues to implementation of EHR.

Although, few of the respondents faced issues in using the system, close to $76.0 \%$ of the respondents chose EHR over paper-based because EHR system is convenient to use, makes data easily accessible, saves time, reduces medical errors, has huge storage capacity and help retrieve patients past medical history. This could be attributed to its quality and efficiency as seen in other studies by [9], who disclosed that EHR has gained prominence in health information reforms in ensuring improved quality, patient satisfaction and fulfilled administrative and transactional needs. [9], established that EHR enhances the quality of healthcare delivery through effective, efficient care and cost savings to both clients and providers. Notwithstanding, about half $(63.0 \%)$ of the respondents were mostly satisfied with the use of the EHR. Result from this current study is in congruence with similar study done by [10] who reported that majority of US health care practitioners asserts that EHR systems improved overall patient care and higher member of their participants were satisfied with their systems.

\section{Benefits of EHR on Quality of Care}

With respect to the benefits of EHR system on quality of care, $80.0 \%$ suggested that EHR system quickens the process of clinical decision-making. Results from this study affirms to similar study by [11] who posit that EHR system is a major mechanism used by managers of hospitals to minimize the cost incurred in the delivery of healthcare services and also improve the health outcomes of their patients. About $82.0 \%$ of the participants declared that EHR system makes it easier to retrieve patients past medical records. This finding agrees with [12] who opined that EHRs provide patients with easy access to data, assist them become more engaged in their healthcare. Fifty percent (50\%) of the respondents strongly agreed that with EHR system the patient waiting time is improved considerably. Similar result was revealed in the study by [13] who posited that time and costs spent on data presentation and communication of information is reduced to the minimum levels. [13] also disclosed that advantages of EHR system include enhanced efficiencies, enhanced precision of health documents, timely and accessible documents.

It is demonstrated in the study that, average number of the respondents agreed that implementing an EHR system improves confidentiality of patient's records. About $72.0 \%$ of the respondents affirmed that EHR system reduces medication and prescription errors.

Similarly, [12] reported that EHR decreases medical mistakes and general healthcare costs by improving the medical documentation and clinical decision support systems. Majority of the respondents established that it is much easier to maintain a patient appointment records using EHR than paper-based. Fifty-three (53\%) percent of the respondents suggested that EHR system improves the overall quality of care offered to patients. Findings from the study are not different from [6] [14] who indicated that EHR adoption has improved the quality of healthcare delivery through effective and efficient care as well as cost savings to both clients and providers.

\section{Challenges Affecting the Implementation and Use of EHR System}

On the challenges affecting the implementation and use of EHR system, the study revealed that most of the respondents had average knowledge regarding the implementation of EHR system since $38.0 \%$ claimed that insufficient training led to fewer competencies in EHR usage. Findings from the present study is similar to another study reported by [15], which concluded that the cost which includes the funds to purchase both hardware and software and cost for training staff in utilizing EHR system remains one of the greatest challenges. Sixty-six (66\%) percent of the respondents asserted that inadequate computer knowledge affected smooth usage of EHR since computer literacy form major contributing factor to the use of EHR and this finding is not different from another study by [16] who opines that computer skill is a key factor in assessing system utilization. In another study, paper-based records are preferred by inexperienced computer users to EHR [16].

Nevertheless, higher number of the respondents insisted that their interaction with EHR system was clear and understandable. Significant number of them refuted the claim that EHR System downtime has not led to user's inability to fully to appreciate the functionality of the implemented EHR system. The study found that frequent downtime lead to EHR system unreliability hence undermining staff interest in utilizing the system. This study is in congruence to a study by [4] who indicated that paper-based records cannot provide flexibility and leverage to Electronic Health Records. The study concluded that most of the respondent had average knowledge on the use and acceptability of the EHR since majority preferred EHR to paper-based records. Another noticeable challenge to EHR use among staff was inadequate training and computer knowledge that inhibit full adoption and utilization.

Based on these findings, it is recommended that

www.sciri.org

(C) 2020, Scientific Research Journal

http://dx.doi.org/10.31364/SCIRJ/v8.i7.2020.P0720786

This publication is licensed under Creative Commons Attribution CC BY. 
- the hospital take proactive steps in training its human resource on the EHR system use. This training program should include activities that can enhance and improve the staff understanding of the EHR system.

- there should be periodic evaluation of the system to help improve the lapses in the system and improved upon it. It is believed; this will improve the knowledge level and overall quality of care among the end users of the implemented Electronic Health Records system.

\section{Conflicts of Interest}

The authors declare no conflicts of interest regarding the publication of this paper.

\section{References}

[1] J.Van der Lei, Information and communication technology in health care: Do we need feedback? International Journal of Medical Informatics, 2012, pp. 75-83.

[2] A. Ismail, The Implementation of Hospital of Hospital System (HIS) in Tertiary Hospitals in Malaysia: A Qualitative Study , Malaysian Journal of Public Health Medicine, 2010, pp. 16-24,

[3] E.K. Acheampong, E. K, Electronic health record system: a survey of Ghanaian Hospitals. Open Access Scientific Reports , 2012, pp. 1-4.

[4] A.K. Jha, C.M. DesRoches, P.D. Kralovec, M.S.Joshi, A progress report on electronic health records in U.S. hospitals. Health Affairs 2009, pp. 1951-195

[5] Canada Health Infoway. An overview of federal and provincial audit reports: Electronic health records in Canada. Minister of Public Works and Government Services Canada 2010.

[6] P. Buttell, R. Hendler, J. Daley, Quality in healthcare: concepts and practice. The business of healthcare, pp. 61-95.

[7] M. Nir, H.C. Taleah, Benefits and drawbacks of electronic health record systems. Risk Management and Healthcare Policy, 2011, pp. 47-55.

[8] R.A. Meehan, T.M. Donald, M. K Kandace, R. Mitra, D. Gary, J. Ritter, M. J. Constance, "Increasing EHR system usability through standards: Conformance criteria in the HL7 EHR-system functional model." Journal of biomedical informatics, 2016, pp. 169-173.

[9] K. Hadwich, D. Georgi, S. Tuzovic, J. Büttner, M. Bruhn, Perceived Quality of Health Services: A Conceptual Scale Development of E-Health Service Quality based on the COAR-SE Approach. International Journal of Pharmaceutical and Healthcare Marketing, 2010, pp.112-136.

[10] B. Jamoom, W. Bercovitz, R. Palso, Physician adoption of electronic health record systems: United States, 2012, pp.1-8

[11] R. G. Fichman, R. Kohli, and R. Krishnan, The role of information systems in healthcare: current research and future trends, Information Systems Research, 2011, pp. 419-428

[12] D. P. Connelly, Y. T. Park, J. Du, N. Theera-Ampornpunt, B. D. Gordon, B.A Bershow, and S. M. Speedie, The impact of electronic health records on care of heart failure patients in the emergency room. Journal of the American Medical Informatics Association, 2011, Pp. 334-340.

[13] S. Aghazadeh, A. Aliyev, M. Ebrahimnezhad, Review the role of hospital information system in medical services development. International Journal of Computer Theory and Engineering, 2012, pp. 866.

[14] S. M. Edworthy, Telemedicine in developing countries. 2011, pp. 524-5.

[15] L. M. Gottlieb, "Moving electronic medical records upstream: incorporating social determinants of health." American journal of preventive medicine, 2015, pp. 215-218.

[16] M. Eijden, H. J. T. Ange, J. T. Roost, A. H. Asman, Determinants of Success of Inpatient Clinical Information Systems: A Literature Review, 2013, pp. 235-243.

www.scirj.org

(C) 2020, Scientific Research Journal

http://dx.doi.org/10.31364/SCIRJ/v8.i7.2020.P0720786

This publication is licensed under Creative Commons Attribution CC BY. 